\title{
BMJ Open Cohort study evaluating pressure ulcer management in clinical practice in the UK following initial presentation in the community: costs and outcomes
}

Julian F Guest, ${ }^{1,2}$ Graham W Fuller, ${ }^{1}$ Peter Vowden, ${ }^{3}$ Kathryn Ruth Vowden ${ }^{3}$

To cite: Guest JF, Fuller GW, Vowden P, et al. Cohort study evaluating pressure ulcer management in clinical practice in the UK following initial presentation in the community: costs and outcomes. BMJ Open 2018;8:e21769. doi:10.1136/ bmjopen-2018-021769

- Prepublication history for this paper is available online. To view these files, please visit the journal online (http://dx.doi. org/10.1136/bmjopen-2018021769).

Received 17 January 2018 Revised 14 March 2018 Accepted 18 April 2018

\section{Check for updates}

${ }^{1}$ Catalyst Health Economics Consultants, Rickmansworth, UK ${ }^{2}$ Faculty of Life Sciences and Medicine, King's College, London, UK

${ }^{3}$ Bradford Teaching Hospitals NHS Foundation Trust, University of Bradford, Bradford, UK

Correspondence to Professor Julian F Guest; julian.guest@catalyst-health. com

\section{ABSTRACT}

Objectives The aim of this study was to estimate the patterns of care and annual levels of healthcare resource use attributable to managing pressure ulcers (PUs) in clinical practice in the community by the UK's National Health Service (NHS), and the associated costs of patient management.

Methods This was a retrospective cohort analysis of the records of 209 patients identified within a randomly selected population of 6000 patients with any type of wound obtained from The Health Improvement Network (THIN) Database, who developed a PU in the community and excluded hospital-acquired PUs. Patients' characteristics, wound-related health outcomes and healthcare resource use were quantified over 12 months from initial presentation, and the corresponding total NHS cost of patient management was estimated at 2015/2016 prices.

Results $50 \%$ of all the PUs healed within 12 months from initial presentation, but this varied between $100 \%$ for category 1 ulcers and $21 \%$ for category 4 ulcers. The mean time to healing ranged from 1.0 month for a category 1 ulcer to 8 months for a category $3 / 4$ ulcer and 10 months for an unstageable ulcer. Patients were predominantly managed in the community by nurses with minimal clinical involvement of specialist clinicians. Up to $53 \%$ of all the ulcers may have been clinically infected at the time of presentation, and $35 \%$ of patients subsequently developed a putative wound infection a mean 4.7 months after initial presentation. The mean NHS cost of wound care over 12 months ranged from $£ 1400$ for a category 1 ulcer to $>£ 8500$ for the other categories of ulcer. Additionally, the cost of managing an unhealed ulcer was 2.4 times more than that of managing a healed ulcer (mean of $£ 5140$ vs $£ 12300$ per ulcer).

Conclusion This study provides important insights into a number of aspects of PU management in clinical practice in the community that have been difficult to ascertain from other studies, and provides the best estimate available of NHS resource use and costs with which to inform policy and budgetary decisions.

\section{INTRODUCTION}

Pressure ulcers (PUs) are localised areas of injury to the skin or underlying tissue, or both, and are caused by external forces

\section{Strengths and limitations of this study}

- This is the first study to evaluate the patient pathways and associated resource use, health outcomes and corresponding costs attributable to managing PUs over 12 months from initial presentation in the community in clinical practice in the UK.

- This study was undertaken using real-world evidence derived from the anonymised records of a sample of patients in the THIN database (a nationally representative database of clinical practice among $>11$ million patients registered with general practitioners (GPS) in the UK)

- The estimates were derived following a systematic analysis of patients' characteristics, wound-related health outcomes and all community-based and secondary care resource use contained in the patients' electronic records.

- Computerised information in the THIN database is collected by GPs for clinical care purposes and not for research, consequently the accuracy of wound descriptors and other terminology have not been validated, but does reflect real-world documentation in clinical practice.

- The analysis does not consider the potential impact of those wounds that remained unhealed beyond the study period nor the potential impact of managing hospital inpatients with a PU and those being cared for in nursing homes/residential homes.

such as pressure, or shear, or a combination of both. ${ }^{1}$ They often occur in areas of bony prominence, such as the sacrum and the heel. ${ }^{2}$ Populations at risk of pressure ulceration include those with spinal cord injuries, ${ }^{3}$ and those immobilised or with limited mobility, such as elderly people and people with acute or chronic conditions that might limit movement or bodily sensation, or both. ${ }^{4}$

The National Pressure Ulcer Advisory Panel, European Pressure Ulcer Advisory Panel (EPUAP) and the Pan Pacific Pressure Injury Alliance have agreed a definition and categorisation of pressure injury. ${ }^{5}$ This states that PUs vary in severity from non-blanchable 
erythema of intact skin (category 1) and partial-thickness skin loss with exposed dermis (category 2) to full-thickness skin loss (category 3) and full-thickness skin and tissue loss (category 4). Some severe ulcers with obscured full-thickness skin and tissue loss are unstageable. ${ }^{5}$ There is agreement across the UK that this categorisation system is used in clinical practice and categories 1-4 are used for incident reporting.

The Burden of Wounds study reported that PUs accounted for $9 \%$ ( $\mathrm{n}=153000$ patients) of all wounds managed by the UK's National Health Service (NHS) in $2012 / 2013 .^{6}$ The annual NHS cost attributable to managing these wounds and associated comorbidities was estimated to be $£ 531.1$ million. ${ }^{7}$ After adjustment for comorbidities, the annual NHS cost was estimated to be between $£ 507.0$ and $£ 530.7$ million. $^{7}$

Wound management is now of such concern that the UK Parliament (House of Lords) debated developing a strategy for improving the standards of wound care in the NHS. ${ }^{8}$ One of the major categories of wounds is $\mathrm{PU}$, and all healthcare systems recognise the importance of PU prevention. Many PUs are avoidable and their prevention is in domain 5 of the Department of Health's NHS outcomes framework 2014/2015. ${ }^{9}$ A successful PU prevention and wound management strategy requires a holistic assessment of the patient, their skin status and their individual risk profile. Management should encompass patient and carer education, repositioning, skin care and the use of suitable pressure relieving devices combined, where necessary, with nutritional support and the use of appropriate wound care products. ${ }^{10}$ Despite this, there is negligible published evidence on the presentation and management of PUs in clinical practice within the community in the UK. Accordingly, the objective of the present analysis was to follow a cohort of patients in clinical practice from initial presentation of a PU in the community to evaluate in greater depth how patients are managed, and the impact of this on healing and NHS costs.

\section{METHODS}

\section{Study design}

This was a retrospective cohort analysis of the case records of patients with a newly diagnosed PU randomly extracted from The Health Improvement Network (THIN) database. The perspective of the analysis was that of the UK's NHS and the time horizon was 12 months from initial presentation in the community.

\section{The Health Improvement Network database}

The THIN database (IMS, London, UK) contains the electronic records of $>11$ million anonymised patients collected from $>550$ general practices across the UK. Read codes are used to code specific diagnoses in the THIN database. ${ }^{11}$ The patient composition within the THIN database has been shown to be representative of the UK population in terms of demographics and disease distribution, ${ }^{12}$ and the database theoretically contains patients' entire medical history, as previously described. ${ }^{6}$ Hence, the information contained in the THIN database reflects actual clinical practice.

\section{Study population}

The authors had previously obtained the electronic records of a random sample of 6000 patients with a wound from the THIN database. The study population of 209 patients was selected from this cohort of 6000 patients according to the following criteria:

- Were 18 years of age or over.

- Had a recorded diagnosis of PU after 2012.

- Had one of the following Read codes for a PU: 39C1.00; 39C2.00; 39C7.00; 39C8.00; 39C9.00; 39CA.00; M270.00; M270.11; M270.14; M270400; M270z00; M271.00; ZQ39.11.

- Had at least 12 months continuous medical history in their case record from the first mention of their PU unless it healed.

Patients with a hospital-acquired PU or those with a dermatological tumour were excluded from the data set. Patients who died within a year of the diagnosis of their PU were also excluded, since the study design was to examine the trajectory of these wounds over a full 12 months from initial presentation unless it healed.

\section{Patient and public involvement}

Patients and members of the public were not directly involved in this study. The study population was limited to the anonymised records of patients in the THIN database.

\section{Study variables and statistical analyses}

Information was systematically extracted from the patients' electronic records over a period of 12 months from initial presentation of their PU. This included patients' characteristics, comorbidities (defined as a non-acute condition that patients were suffering from in the year before the start of their wound), wound-related healthcare resource use (ie, dressings, bandages, topical treatments, negative pressure wound therapy, district nurse visits (who provide care within a patient's home), practice nurse visits (who provide care within a general practitioner's (GP's) surgery), GP visits, hospital outpatient visits, laboratory tests), prescribed medication (ie, analgesics, non-steroidal anti-inflammatory drugs (NSAIDs) and systemic anti-infectives (principally antibiotics)) and clinical outcomes (ie, healing and putative infection). If a patient received a bandage or dressing on a specific date, but a clinician visit was not documented in their record, it was assumed the patient had been seen outside of the general practice by a district nurse. No other assumptions were made regarding missing data and there were no other interpolations.

The use of individual healthcare resources was quantified for all the patients, individually. These quantities were then used to estimate the mean amount of individual healthcare resource use attributable to managing 
a PU over 12 months from initial presentation in the community. Healthcare resource use was also estimated by stratifying patients according to their category of PU.

Differences between two subgroups were tested for statistical significance using a Mann-Whitney U test or $\chi^{2}$ test. Differences between three subgroups were tested for statistical significance using a Kruskal-Wallis test or $\chi^{2}$ test. Logistic regression was used to investigate relationships between baseline variables and clinical outcomes. Kaplan-Meier analyses were undertaken to compare the healing distribution of different subgroups. The $p$ values $<0.05$ were considered statistically significant and have been reported. All $p$ values $\geq 0.05$ were not considered to be statistically significant and these numerical values have not been reported. All statistical analyses were performed using IBM SPSS Statistics (IBM UK, Portsmouth, Hampshire, UK).

\section{Cost of patient management}

The NHS cost of wound care for each patient was estimated by assigning unit costs at $2015 / 2016$ prices $^{13-15}$ to the quantity of healthcare resource used by individual patients. The mean cost of utilisation of each healthcare resource was then combined in order to estimate the mean NHS cost of managing a PU over 12 months from initial presentation in the community. The cost of wound care was also estimated by stratifying patients according to their category of PU. Accordingly, the study only considers the cost of patient management attributable to a PU and does not estimate patients' overall healthcare costs.

The estimated cost of patient management excluded those borne by non-NHS organisations for providing pressure relieving equipment and other aids by Social Services. Also excluded were the costs of any nutritional supplements.

\section{Sensitivity analyses}

Deterministic sensitivity analyses were undertaken to assess how the cost of PU management changes by varying the values of clinical outcomes and resource use.

\section{RESULTS}

\section{Patients' characteristics}

According to the patients' records, the 209 patients in the data set had only one PU. If a patient had multiple PUs, it was not documented. Eleven per cent of patients had a category $1 \mathrm{PU}, 7 \%$ had a category $2 \mathrm{PU}, 60 \%$ had a category $3 \mathrm{PU}, 10 \%$ had a category $4 \mathrm{PU}$ and $12 \%$ had an unstageable PU. The patients' age was a mean of 77.2 years per patient; $87 \%$ of the cohort were $>60$ years of age. However, $9 \%$ were $\leq 50$ years of age. Patients' baseline characteristics are summarised in table 1.

Thirty-five per cent of patients acquired their wound within 3 months of hospital discharge of which 17\% occurred within a month of discharge, 9\% within 1-2 months and $10 \%$ within 2-3 months. Sixty-five per cent of

\begin{tabular}{|lc|}
\hline Table 1 Patients' baseline characteristics & \\
\hline Mean age per patient (years) & 77.2 \\
\hline Percentage female & $61 \%$ \\
\hline Mean systolic blood pressure per patient $(\mathrm{mm} \mathrm{Hg})$ & 126.1 \\
\hline Mean diastolic blood pressure per patient $(\mathrm{mm} \mathrm{Hg})$ & 71.8 \\
\hline Mean BMI per patient (kg/m²) & 24.3 \\
\hline Percentage with BMI $<18.5 \mathrm{~kg} / \mathrm{m}^{2}$ & $15 \%$ \\
\hline Percentage with BMI $\geq 18.5-24.9 \mathrm{~kg} / \mathrm{m}^{2}$ & $28 \%$ \\
\hline Percentage with BMI $\geq 25.0 \mathrm{~kg} / \mathrm{m}^{2}$ & $44 \%$ \\
\hline Percentage with unknown BMI & $13 \%$ \\
\hline Percentage with a category $1 \mathrm{PU}$ & $11 \%$ \\
\hline Percentage with a category 2 PU & $7 \%$ \\
\hline Percentage with a category 3 PU & $60 \%$ \\
\hline Percentage with a category $4 \mathrm{PU}$ & $10 \%$ \\
\hline Percentage with an unstageable PU & $12 \%$ \\
\hline Percentage who were wheelchair users & $9 \%$ \\
\hline
\end{tabular}

$\mathrm{BMI}$, body mass index; PU, pressure ulcer.

patients had no recorded history of a hospital admission in their record in the 12 months from initial presentation of their wound.

The patients had a mean of 5.8 comorbidities per patient and this was not significantly different between those with a different category of PU. Patients with a category $1 \mathrm{PU}$ had a mean of 6.4 comorbidities per patient. Those with a category 2, 3 or $4 \mathrm{PU}$ had a mean of 6.0, 5.7 and 6.2 comorbidities per patient, respectively. Patients with an unstageable PU had a mean of 5.9 comorbidities per patient; and $44 \%$ of all the patients had diabetes. Patients' comorbidities are summarised in table 2. There were no significant differences in the incidence of comorbidities between patients whose PU healed and those whose wound did not heal within 12 months from initial presentation.

Nine per cent of the patients were wheelchair users. The mean age of this cohort was 64.2 years per patient (range 24-91 years), of which $26 \%$ were $<50$ years of age. Of the $9 \%, 2 \%$ of these patients had a category 1 PU, $2 \%$ had a category 2 PU, $5 \%$ had a category 3 PU and $<1 \%$ had a category 4 PU.

\section{Diagnosis and patient management}

Sixty per cent of the PUs were first recorded in the patients' records by GPs, $18 \%$ by district nurses, $14 \%$ by practice nurses and $8 \%$ by other healthcare professionals. Location of the ulcer was not specified in $>95 \%$ of cases. However, $23 \%$ of patients received prescriptions for bandages which may indicate that at least $23 \%$ of the wounds were on a limb, as not all lower limb PUs would necessarily require a bandage as part of their management. Additionally, $50 \%$ of patients with a category $1 \mathrm{PU}$ did not receive any dressings.

Patients' initial treatment (table 3) varied according to category of PU (table 4). Patients continued to be 
Table 2 Patients' comorbidities

\section{Percentage of patients with comorbidity}

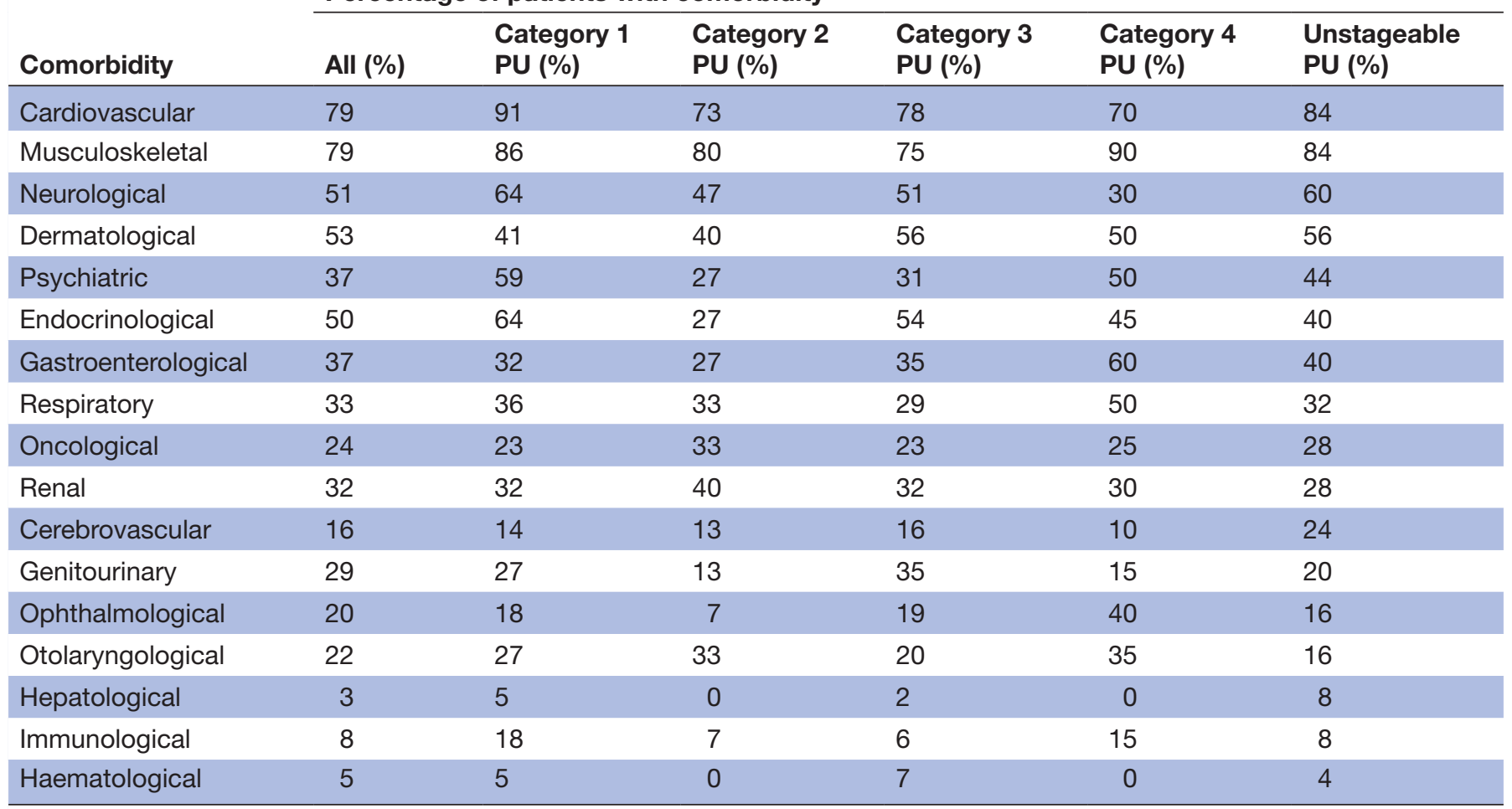

$\mathrm{PU}$, pressure ulcer.

prescribed their initial mix of dressings until such time as their wound healed (table 3). Nearly half the patients received multiple dressings in the first month of treatment decreasing to $12 \%$ of patients by the 12 th month of treatment (figure 1). Patients who were treated with multiple dressings received between a mean of two and three dressings. Additionally, $2 \%$ of patients with a category $3 \mathrm{PU}$ and $5 \%$ of those with a category $4 \mathrm{PU}$ received negative pressure wound therapy.
Overall, patients' dressings were changed twice a week. However, this varied according to category of ulcer.

- Those with a category 1 PU had one nursing visit/ dressing change per week.

- Those with a category 2 PU had three dressing changes per 2 weeks

- Those with a category 3 PU had two dressing changes per week.

\begin{tabular}{|c|c|c|c|c|c|c|c|c|c|c|}
\hline \multirow[b]{2}{*}{$\begin{array}{l}\text { Month of } \\
\text { treatment }\end{array}$} & \multicolumn{10}{|c|}{ Percentage of patients who were treated with the following dressings } \\
\hline & $\begin{array}{l}\text { Soft } \\
\text { polymer } \\
(\%)\end{array}$ & $\begin{array}{l}\text { Unspecified } \\
(\%)\end{array}$ & $\begin{array}{l}\text { Foam } \\
(\%)\end{array}$ & $\begin{array}{l}\text { Antimicrobial } \\
\text { (\%) }\end{array}$ & $\begin{array}{l}\text { Hydrocolloid } \\
\text { (\%) }\end{array}$ & $\begin{array}{l}\text { Absorbent } \\
(\%)\end{array}$ & $\begin{array}{l}\text { Permeable } \\
\text { (\%) }\end{array}$ & $\begin{array}{l}\text { Hydrogel } \\
\text { (\%) }\end{array}$ & $\begin{array}{l}\text { Alginate } \\
(\%)\end{array}$ & $\begin{array}{l}\text { Low } \\
\text { adherence } \\
(\%)\end{array}$ \\
\hline 1 & 20 & 16 & 17 & 14 & 14 & 7 & 5 & 4 & 3 & 1 \\
\hline 2 & 21 & 12 & 17 & 17 & 12 & 8 & 4 & 3 & 5 & 1 \\
\hline 4 & 21 & 11 & 18 & 14 & 12 & 10 & 5 & 5 & 4 & 1 \\
\hline 5 & 21 & 15 & 17 & 13 & 11 & 9 & 6 & 3 & 5 & 0 \\
\hline 6 & 20 & 11 & 20 & 15 & 12 & 10 & 5 & 3 & 4 & 0 \\
\hline 7 & 24 & 11 & 16 & 14 & 11 & 11 & 3 & 5 & 4 & 1 \\
\hline 8 & 21 & 14 & 21 & 15 & 8 & 10 & 3 & 3 & 3 & 1 \\
\hline 12 & 20 & 14 & 23 & 13 & 9 & 9 & 2 & 2 & 5 & 2 \\
\hline
\end{tabular}


Table 4 Dressings prescribed at the time of initial presentation

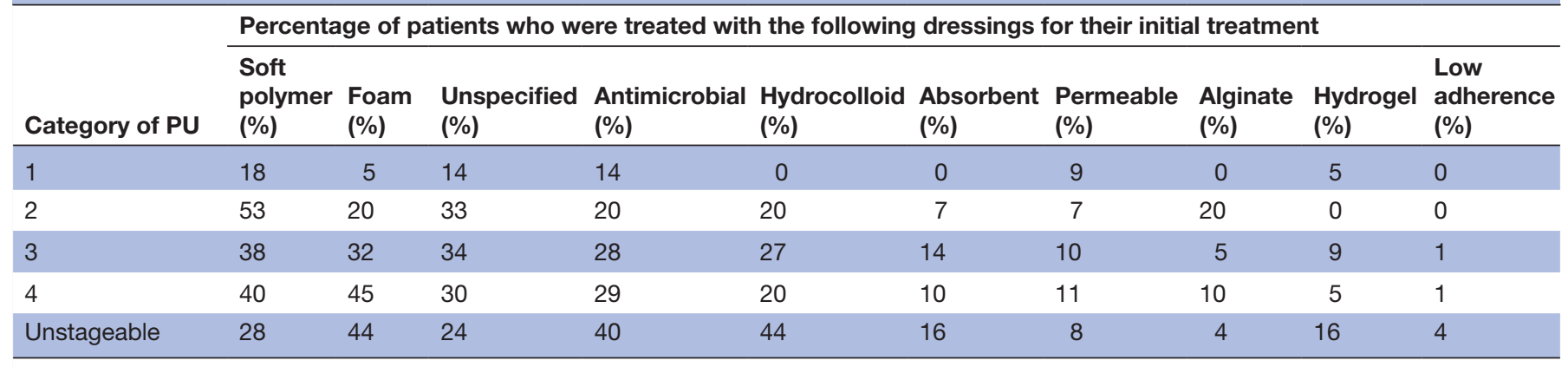

$\mathrm{PU}$, pressure ulcer.

- Those with a category 4 PU had three dressing changes per week

- Those with an unstageable PU had two dressing changes per week.

In addition to dressings and bandages, $94 \%$ of patients were prescribed an analgesic or NSAID, and $18 \%$ were prescribed a systemic anti-infective at the time of diagnosis. Over the study period, $53 \%$ of all patients were prescribed a systemic anti-infective, although it is not possible to confirm if this was wound-related, and $50 \%$ of all patients received an antimicrobial dressing.

Healthcare resource use associated with managing a PU in clinical practice is shown in table 5. Patients were predominantly managed in the community by nurses. Resource use associated with managing a category $1 \mathrm{PU}$ was substantially less than that associated with managing the other categories of PU. Only 12\% of patients were recorded as having seen a specialist physician in the 12 months from initial presentation, of which $65 \%$ of the patients had a category 3 ulcer. The other $35 \%$ of the patients had an equal mix of all the other categories. There was no evidence of $33 \%$ of patients having seen their GP during the 12 months from initial presentation and $<2 \%$ of patients saw a dietitian.

The records documented that only six patients had direct tissue viability nurse input in their care, with whom they had a mean of two visits. Four of these six patients had a category 3 ulcer and two patients had an unstageable ulcer.

\section{Clinical outcomes}

In accordance with the study's inclusion criteria, all the patients in our data set survived the period of 12 months following initial presentation. Fifty per cent of all the PUs healed within 12 months from diagnosis (figure 2), and the time to healing among the healed patients was a mean of 5.4 months per patient. However, this varied according to category. The time to healing was a mean of 1.1 months per patient with a category $1 \mathrm{PU}, 5.0$ months per patient with a category $2 \mathrm{PU}, 7.7$ months per patient with a category 3 or $4 \mathrm{PU}$ and 10.0 months per patient with an unstageable PU.

The distribution of healing between the different categories of PU were significantly different $(p<0.001)$

\section{Percentage of patients}

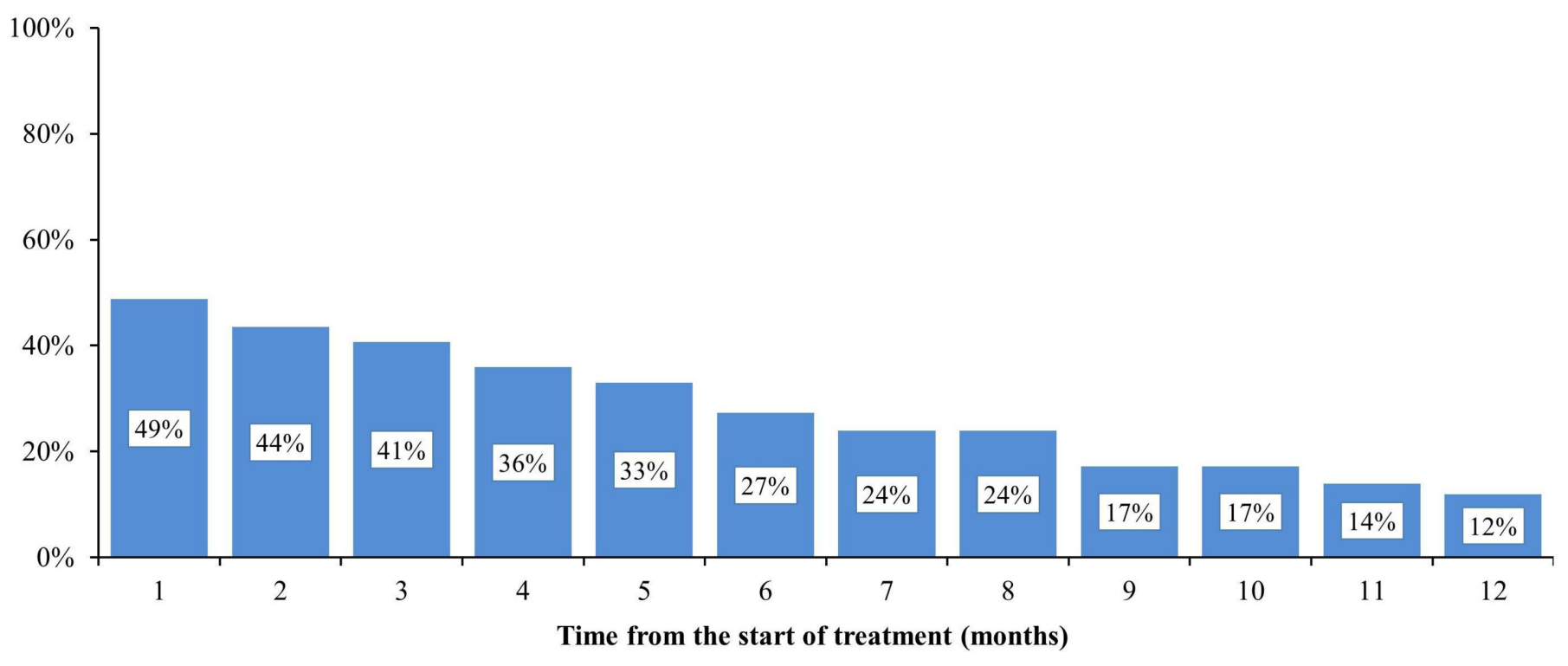

Figure 1 Patients who received multiple dressings. 
Table 5 Healthcare resource use associated with managing PUs in clinical practice

Mean amount of resource use per patient over 12 months from initial presentation

\begin{tabular}{|c|c|c|c|c|c|c|}
\hline Resource use & All & $\begin{array}{l}\text { Category } 1 \\
\text { PU }\end{array}$ & $\begin{array}{l}\text { Category } \\
2 \text { PU }\end{array}$ & $\begin{array}{l}\text { Category } 3 \\
\text { PU }\end{array}$ & $\begin{array}{l}\text { Category } \\
\text { 4PU }\end{array}$ & $\begin{array}{l}\text { Unstageable } \\
\text { PU }\end{array}$ \\
\hline District nurse visits & 101.56 & 23.50 & 99.33 & 109.14 & 141.40 & 101.20 \\
\hline Dressings & 196.97 & 29.59 & 207.00 & 211.33 & 252.90 & 217.36 \\
\hline Prescriptions for analgesics and NSAIDs & 7.00 & 0.91 & 4.33 & 6.76 & 13.10 & 10.24 \\
\hline Bandages & 15.46 & 0.59 & 20.53 & 16.30 & 20.48 & 17.24 \\
\hline Prescriptions for anti-infectives & 1.46 & 0.05 & 1.60 & 2.40 & 2.80 & 1.70 \\
\hline General practitioner visits & 1.20 & 0.59 & 0.93 & 1.21 & 1.60 & 1.56 \\
\hline Practice nurse visits & 2.30 & 0.95 & 2.00 & 2.24 & 3.70 & 2.60 \\
\hline Negative pressure wound therapy & 0.47 & 0.00 & 0.00 & 0.54 & 1.50 & 0.00 \\
\hline Hospital outpatient visits & 0.16 & 0.14 & 0.20 & 0.17 & 0.00 & 0.24 \\
\hline Topical treatments & 6.54 & 0.00 & 8.00 & 8.44 & 10.50 & 0.00 \\
\hline Laboratory tests & 0.03 & 0.05 & 0.07 & 0.02 & 0.15 & 0.00 \\
\hline
\end{tabular}

NSAID, non-steroidal anti-inflammatory drug; PU, pressure ulcer.

(figure 2). All the category 1 PUs resolved within 12 months of diagnosis compared with $69 \%$ of category 2 PUs, $41 \%$ of category 3 PUs, $21 \%$ of category 4 PUs and $36 \%$ of unstageable PUs.

At the end of 12 months, $42 \%$ of patients with a BMI of $<18.5 \mathrm{~kg} / \mathrm{m}^{2}$ had a healed PU compared with $53 \%$ of patients who had a BMI of $\geq 18.5$ to $\leq 24.9 \mathrm{~kg} / \mathrm{m}^{2}$ and $51 \%$ of patients who had a BMI of $\geq 25.0 \mathrm{~kg} / \mathrm{m}^{2}$ (figure 3 ). Furthermore, the time to healing was lengthened in those patients with a BMI of $<18.5 \mathrm{~kg} / \mathrm{m}^{2}$ (7.0 vs 4.9 months per patient). These differences did not reach statistical significance. Additionally, the PU of $43 \%$ of patients with diabetes healed over the 12 months follow-up period compared with $44 \%$ of patients without diabetes.

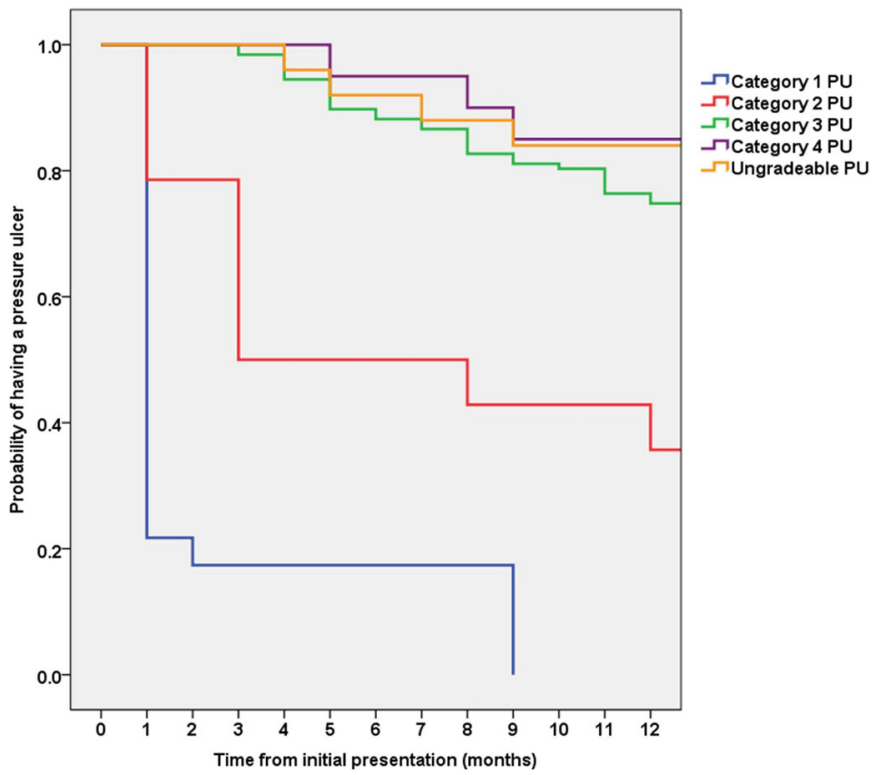

Figure 2 Kaplan-Meier time to healing analysis. The healing distribution between the five groups was significantly different (log rank (Mantel-Cox): $\mathrm{p}<0.0001$ ). PU, pressure ulcer.
However, the time to healing was lengthened in those patients with diabetes (5.5 vs 4.7 months per patient).

\section{Cost of patient management}

The mean NHS cost of wound care in clinical practice over 12 months was an estimated $£ 8720$ per PU. However, this varied between $£ 1382$ per patient with a category 1 PU and $>£ 8500$ per patient with a category 2,3 or 4 PU or an unstageable PU (table 6). The cost of managing a PU that remained unhealed at 12 months was 2.4 times more than that of managing a healed PU ( $£ 5140$ per healed PU vs $£ 12300$ per unhealed PU) (table 7). Figure 4 illustrates how the monthly cost of PU management varies for all categories of PU.

District nurse visits were the primary cost driver and accounted for $\geq 80 \%$ of the cost of patient management. Dressings and bandages accounted for up to $15 \%$ of the cost of patient management. Of the total NHS cost of managing this cohort of PUs, $98 \%$ was incurred in the community and the remainder in secondary care. Furthermore, the distribution of costs was unaffected by category of ulcer or whether the wound healed.

Among patients with a BMI $<18.5 \mathrm{~kg} / \mathrm{m}^{2}$, the mean NHS cost of wound care over 12 months was $£ 9460$ per patient compared with $£ 8620$ per patient for those with a BMI $\geq 18.5 \mathrm{~kg} / \mathrm{m}^{2}$. Additionally, the mean NHS cost of wound care over 12 months was $£ 8620$ per patient with diabetes and $£ 8800$ per patient without diabetes.

\section{Infection}

Fourteen per cent of the patients' records documented their PU as being clinically infected at the time of presentation. Another 39\% of patients were prescribed a systemic anti-infective or antimicrobial dressing at the initial presentation, suggesting that as many as $53 \%$ of all the wounds in our data set may have been considered to be at risk of infection or infected at the time of the initial 


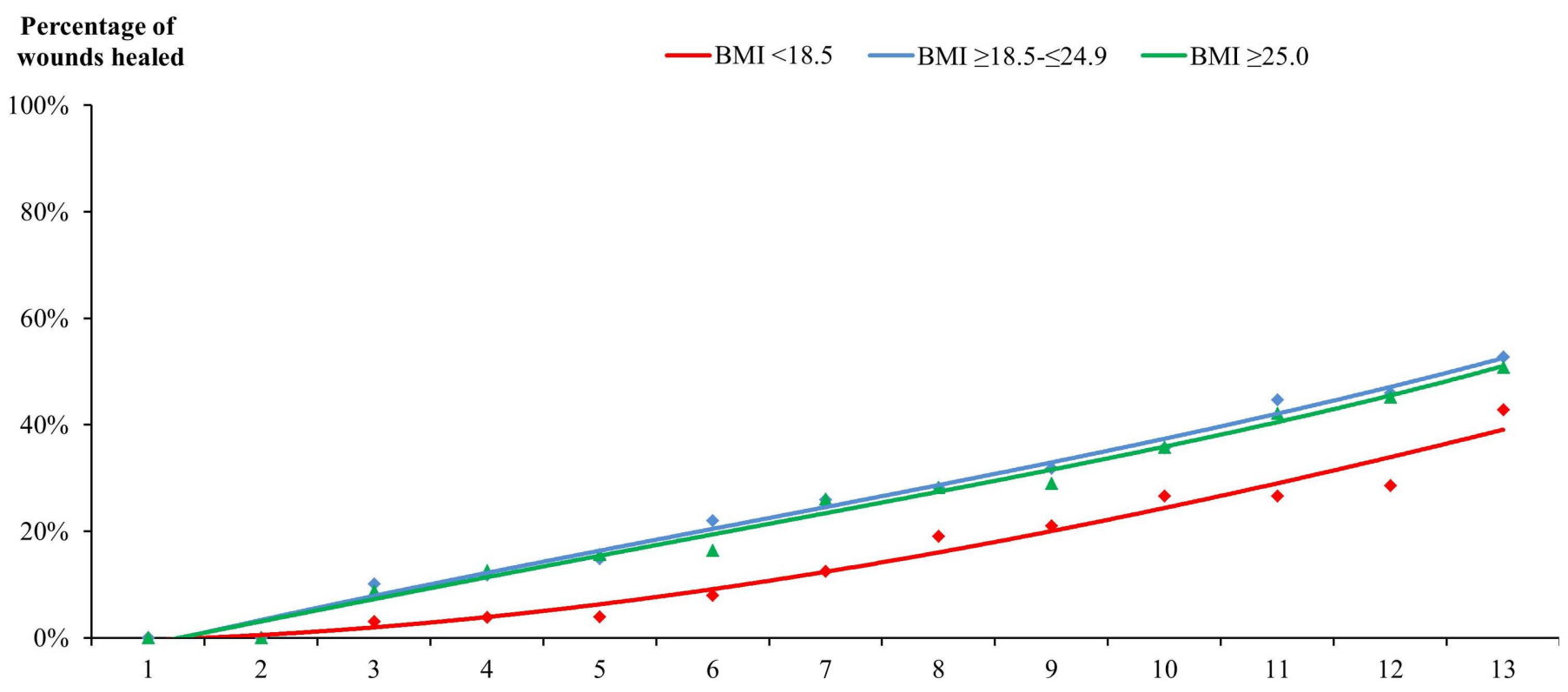

Time from wound onset (months)

Figure 3 Wound healing stratified by body mass index $\left(\mathrm{BMI}, \mathrm{kg} / \mathrm{m}^{2}\right)$.

presentation. Furthermore, $32 \%$ of all patients had no recorded infection or antimicrobial dressing prescribed over the 12 months follow-up period (table 8).

According to documentation in the patients' records, $53 \%$ of patients were prescribed a systemic anti-infective for a mean of 1.4 months per patient. Additionally, 15\% of patients received only a topical antimicrobial, indicative of concern about the local bioburden or a possible localised wound infection. The duration of continuous prescribing of a topical antimicrobial was a mean of 3.5 months per patient. However, $10 \%$ of patients received continuous prescribing of a topical antimicrobial for $>6$ months.

Of the $32 \%$ of patients who did not have an infection, $40 \%$ of the PUs healed within a mean of 3.4 months. The PU healing rate was significantly lower among patients with a putative infection $(\mathrm{p}<0.005)$, and the mean time to healing was significantly longer $(p=0.001)$ (table 8$)$. Furthermore, the cost of wound management of an uninfected PU was at least $37 \%$ less than that of a wound with a putative infection $(\mathrm{p}<0.001)$ (table 8$)$. The percentage of putative infections and associated costs varied according to category of PU (table 9).

Fifteen per cent of patients subsequently developed a confirmed or suspected wound infection a mean 4.7 months after initial presentation. The cost of wound management among these patients was a mean $£ 9437$ per patient.

If prescribing of (1) antimicrobial dressings and (2) systemic anti-infectives is a proxy for a suspected infection, then it can be inferred that healing was impaired among patients who were considered to have an infection (figures 5-7). Binary logistic regression showed that within the limitations of the data documented in the records, the presence of a putative infection (ie, patients who were prescribed an antimicrobial dressing and/or a systemic anti-infective) was an independent risk factor for decreased healing (OR $0.294,95 \%$ CI 0.154 to 0.559 ; $\mathrm{p}<0.001$ ).

\section{Sensitivity analyses}

Sensitivity analysis showed that if the probability of healing was reduced by $25 \%$, from $50 \%$ to $38 \%$, the mean NHS cost of wound care over 12 months would increase by $10 \%$ to an estimated $£ 9614$ per PU. Conversely, if the probability of healing was increased by $25 \%$, from $50 \%$ to $63 \%$, the mean NHS cost of wound care over 12 months would decrease by $10 \%$ to an estimated $£ 7825$ per PU. If the unit cost of wound care products was decreased or increased by $25 \%$, the mean NHS cost of wound care over 12 months would only vary by $3 \%$ from the mean value (range $£ 8435-£ 9004$ per PU). However, if the number of district nurse visits changed by $25 \%$ below or above the base case value, the mean NHS cost of wound care over 12 months would vary by $20 \%$ from the mean value (range £6939-£10500 per PU). Conversely, if the number of practice nurse visits changed by $25 \%$ below or above the base case value, the mean NHS cost of wound care over 12 months would vary by $<1 \%$ from the mean value (range $£ 8701-£ 8738$ per PU). If the number of GP visits changed by $25 \%$ below or above the base case value, the mean NHS cost of wound care over 12 months would vary by $<1 \%$ from the mean value (range $£ 8693-£ 8746$ per $\mathrm{PU})$. Changes to the use of other resources had a minimal impact on the mean NHS cost of wound care in clinical practice.

\section{DISCUSSION}

The population reported in this study are those patients who developed a PU in the community and survived for at least a year following diagnosis, and may well be different 


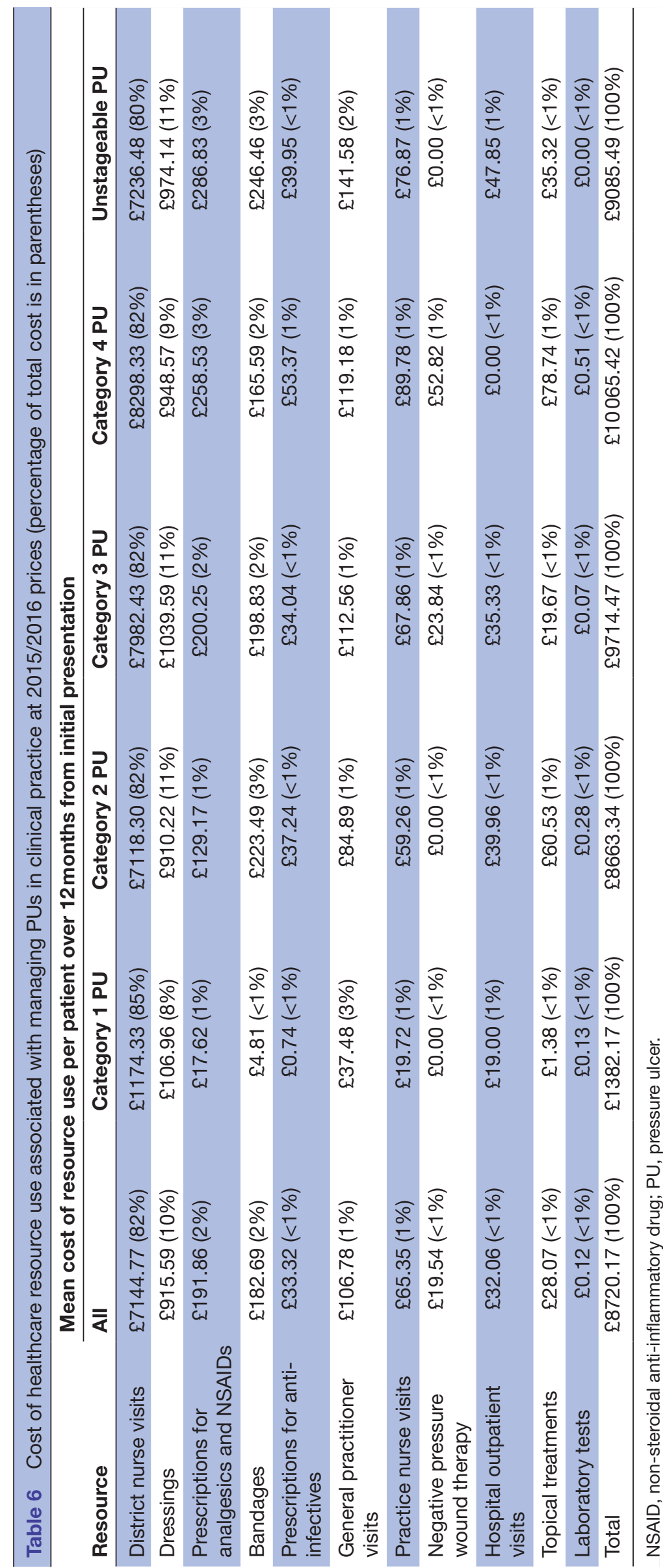

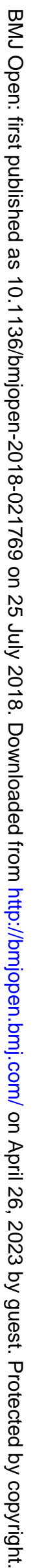


Table 7 Cost of healthcare resource use associated with managing healed and unhealed PUs in clinical practice at 2015/2016 prices (percentage of total cost is in parenthesis)

\section{Mean cost of resource use per patient over 12 months from initial presentation}

\begin{tabular}{|c|c|c|}
\hline Resource & Healed PU & Unhealed PU \\
\hline District nurse visits & $£ 4133.58(80 \%)$ & $£ 10108.79(82 \%)$ \\
\hline Dressings & $£ 530.00(10 \%)$ & $£ 1277.43(10 \%)$ \\
\hline $\begin{array}{l}\text { Prescriptions for } \\
\text { analgesics and } \\
\text { NSAIDs }\end{array}$ & $£ 102.48(2 \%)$ & $£ 276.56(2 \%)$ \\
\hline Bandages & $£ 141.61(3 \%)$ & $£ 257.03(2 \%)$ \\
\hline $\begin{array}{l}\text { Prescriptions for } \\
\text { anti-infectives }\end{array}$ & $£ 9.93(<1 \%)$ & $£ 51.97(<1 \%)$ \\
\hline $\begin{array}{l}\text { General practitioner } \\
\text { visits }\end{array}$ & $£ 80.62(2 \%)$ & $£ 134.48(1 \%)$ \\
\hline Practice nurse visits & $£ 72.95(1 \%)$ & $£ 74.49(1 \%)$ \\
\hline $\begin{array}{l}\text { Negative pressure } \\
\text { wound therapy }\end{array}$ & $£ 0.00(<1 \%)$ & $£ 47.60(<1 \%)$ \\
\hline $\begin{array}{l}\text { Hospital outpatient } \\
\text { visits }\end{array}$ & $£ 36.08(1 \%)$ & $£ 33.71(<1 \%)$ \\
\hline Topical treatments & $£ 35.73(1 \%)$ & $£ 33.83(<1 \%)$ \\
\hline Laboratory tests & $£ 0.07(<1 \%)$ & $£ 0.17(<1 \%)$ \\
\hline Total & $£ 5143.05(100 \%)$ & $£ 12296.06(100 \%)$ \\
\hline
\end{tabular}

NSAID, non-steroidal anti-inflammatory drug; PU, pressure ulcer.

to the cohort of patients who develop a hospital-acquired PU while being an inpatient. The THIN database does not define what a PU is. Instead, it was a clinical diagnosis by the nurses/GPs who managed these patients, although it is unknown whether they used any consistent definition or categorisation system, such as the recommended EPUAP classification system. ${ }^{5}$ Nevertheless, it is the authors' understanding that this analysis provides the first study of how PUs are diagnosed and managed in clinical practice in the community in the UK.

Our analysis suggests that PUs are often complex wounds occurring in patients with significant comorbidity, the management of which is associated with significant resource use. Wound management is a major cost item in the overall NHS budget. ${ }^{6}$ The Burden of Wounds study ${ }^{6716}$ identified the major cost drivers within the overall wound care budget and provided insight into areas where care improvements could potentially result in improved clinical outcomes while generating cost savings. This analysis found the mean NHS cost of wound care over 12 months from initial presentation to be an estimated $£ 8700$ per PU. However, this ranged from $£ 1400$ for a category 1 PU to $>£ 8500$ for the other categories. These costs are consistent with those reported by Bennett et $a l^{17}$ and subsequently updated by Dealey $e t a l,{ }^{18}$ who estimated the cost of treating a PU varies from $£ 1214$ (category 1) to £14 108 (category 4) at 2011 prices. They also found that costs increase with ulcer severity and that the cost per episode increased if the wound became infected ${ }^{18}$ consistent with the findings reported in this study.

Moreover, at least half of all the PUs in this data set were considered to be at risk of infection or infected at the time of presentation. This estimate was based on documentation of infection in the patients' records and the use of antimicrobial dressings and anti-infective prescriptions. The authors recognise the potential weakness of this estimate as systemic anti-infectives are frequently prescribed in general practice on the basis of wound swabs, and this is openly criticised by microbiology and infectious disease experts worldwide.

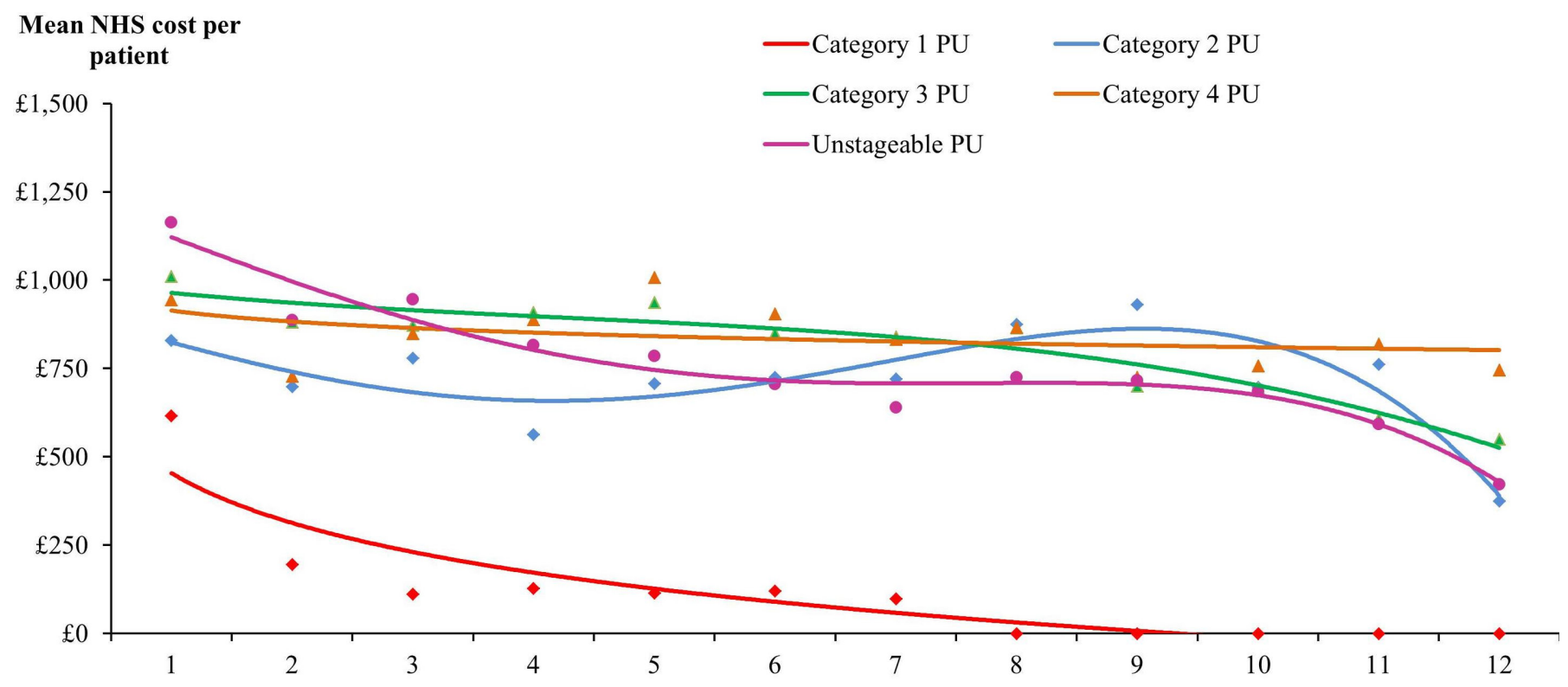

Time from wound onset (months)

Figure 4 Monthly cost of wound care. NHS, National Health Service; PU, pressure ulcer. 
Table 8 Incidence of putative infection with associated healing and costs

\begin{tabular}{|c|c|c|c|c|}
\hline & $\begin{array}{l}\text { Percentage } \\
\text { of } \\
\text { patients (\%) }\end{array}$ & $\begin{array}{l}\text { Percentage of } \\
\text { patients who } \\
\text { healed }(\%)\end{array}$ & $\begin{array}{l}\text { Mean time to } \\
\text { healing per patient } \\
\text { (months) }\end{array}$ & $\begin{array}{l}\text { Mean cost of } \\
\text { wound care per } \\
\text { patient (£) }\end{array}$ \\
\hline No infection & 32 & 40 & 3.37 & 4662 \\
\hline Prescribed an anti-infective with or without an antimicrobial dressing & 53 & 14 & 7.73 & 10906 \\
\hline Prescribed an anti-infective with an antimicrobial dressing & 35 & 13 & 8.44 & 13341 \\
\hline
\end{tabular}

Furthermore, antimicrobial dressings are prescribed prophylactically in clinical practice for wounds that are both infected and uninfected. The relative effects of systemic and topical antimicrobial treatments on PUs are unclear, ${ }^{19}$ and the National Institute for Health and Care Excellence (NICE) recommends that topical antimicrobials and antiseptics should not be routinely used to treat a PU in adults. ${ }^{10}$

Table 9 Incidence of putative infection with associated healing and costs stratified by category of PU

\begin{tabular}{|c|c|c|c|c|}
\hline & $\begin{array}{l}\text { Percentage of } \\
\text { cohort }(\%)\end{array}$ & $\begin{array}{l}\text { Percentage } \\
\text { of cohort that } \\
\text { healed }(\%)\end{array}$ & $\begin{array}{l}\text { Mean time } \\
\text { to healing } \\
\text { per patient } \\
\text { (months) }\end{array}$ & $\begin{array}{l}\text { Mean cost of } \\
\text { wound care per } \\
\text { patient }(£)\end{array}$ \\
\hline \multicolumn{5}{|l|}{ Category $1 \mathrm{PU}$} \\
\hline No infection & 82 & 100 & 1.17 & 741 \\
\hline Received only an antimicrobial dressing & 18 & 100 & 4.00 & 4446 \\
\hline Prescribed an anti-infective & 0 & & & \\
\hline \multicolumn{5}{|l|}{ Category 2 PU } \\
\hline No infection & 53 & 57 & 4.86 & 3516 \\
\hline Received only an antimicrobial dressing & 47 & 0 & & 12103 \\
\hline Prescribed an anti-infective & 0 & & & \\
\hline \multicolumn{5}{|l|}{ Category 3 PU } \\
\hline No infection & 27 & 23 & 6.63 & 4828 \\
\hline Received only an antimicrobial dressing & 20 & 16 & 7.96 & 7266 \\
\hline Prescribed an anti-infective & 53 & 15 & 8.40 & 9589 \\
\hline $\begin{array}{l}\text { Prescribed an anti-infective with an antimicrobial } \\
\text { dressing }\end{array}$ & 36 & 11 & 9.00 & 11049 \\
\hline Prescribed only an anti-infective & 17 & 24 & 7.80 & 6390 \\
\hline \multicolumn{5}{|l|}{ Category 4 PU } \\
\hline No infection & 24 & 0 & & 7609 \\
\hline Received only an antimicrobial dressing & $<1$ & & & \\
\hline Prescribed an anti-infective & 75 & 20 & 7.33 & 16289 \\
\hline $\begin{array}{l}\text { Prescribed an anti-infective with an antimicrobial } \\
\text { dressing }\end{array}$ & 45 & 33 & 7.33 & 16446 \\
\hline Prescribed only an anti-infective & 30 & 0 & & 16054 \\
\hline \multicolumn{5}{|l|}{ Unstageable PU } \\
\hline No infection & 19 & 25 & 5.00 & 3387 \\
\hline Received only an antimicrobial dressing & $<1$ & & & \\
\hline Prescribed an anti-infective & 80 & 5 & 9.00 & 8109 \\
\hline $\begin{array}{l}\text { Prescribed an anti-infective with an antimicrobial } \\
\text { dressing }\end{array}$ & 48 & 8 & 9.00 & 8988 \\
\hline Prescribed only an anti-infective & 32 & 0 & & 6791 \\
\hline
\end{tabular}

$\mathrm{PU}$, pressure ulcer. 


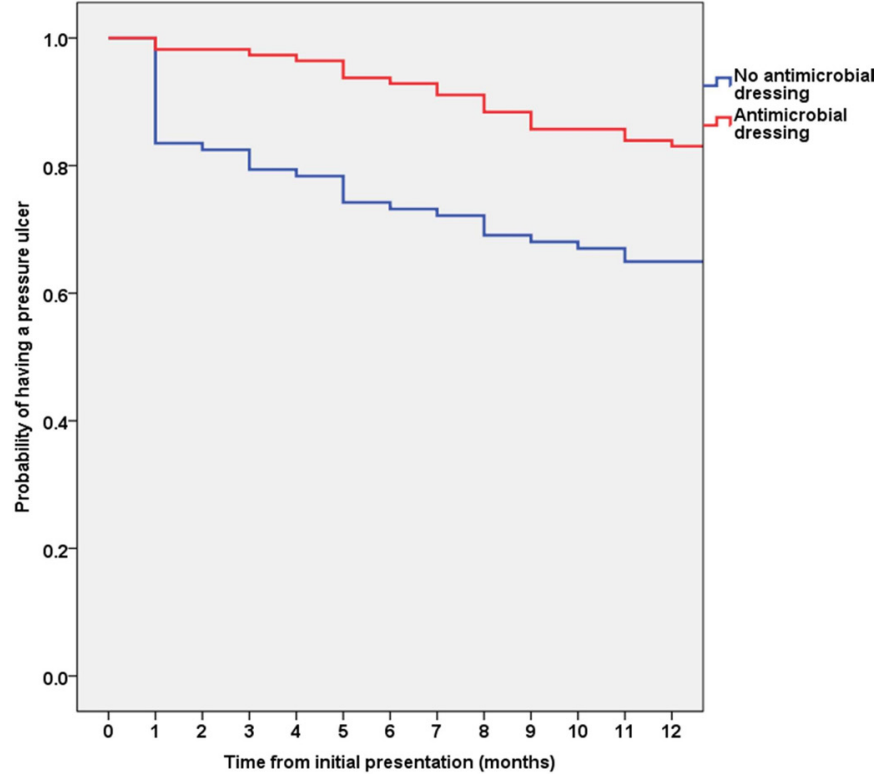

Figure 5 Kaplan-Meier time to healing analysis for patients who did and did not receive antimicrobial dressings. The healing distribution between the two groups was significantly different (log rank (Mantel-Cox): $p=0.006$ ).

Notwithstanding this, resource use associated with managing a putative infected wound was found to be greater than that of an uninfected wound as the healing rate was lower and time to healing was longer. So too was resource use associated with managing unhealed PUs compared with healed wounds. Consequently, the cost of managing an unhealed PU was 2.4 times more than that of managing a healed PU ( $\$ 5140$ per healed PU vs $£ 12300$ per unhealed PU), and the cost of managing a putative infected wound was at least 1.5 times more than that of an

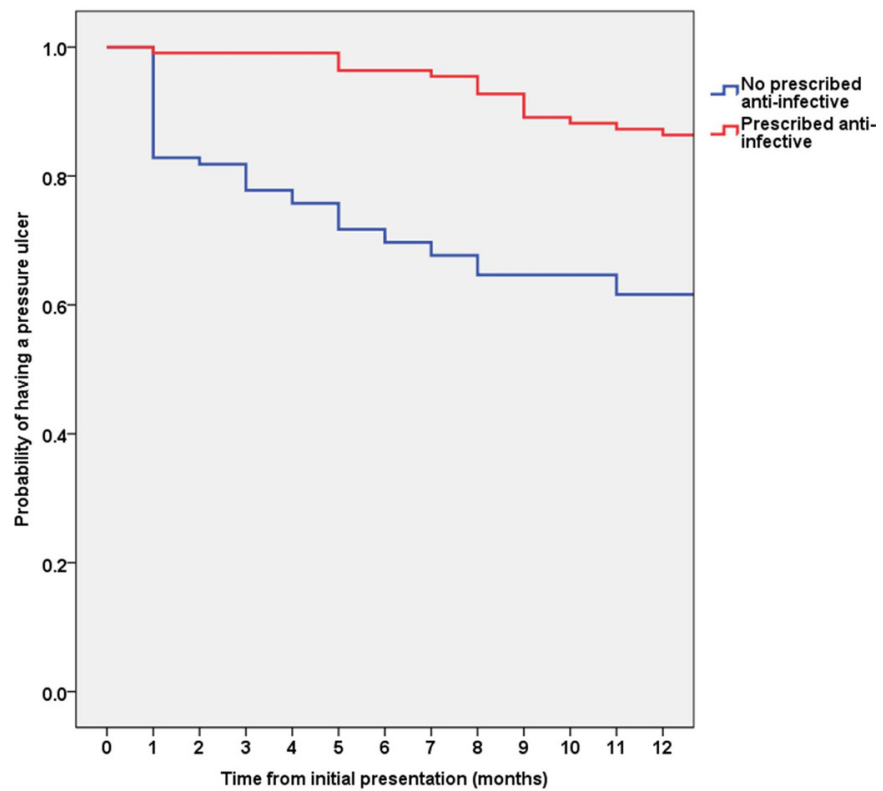

Figure 6 Kaplan-Meier time to healing analysis for patients who did and did not receive prescribed systemic antiinfectives. The healing distribution between the two groups was significantly different (log rank (Mantel-Cox): $p<0.001$ ).

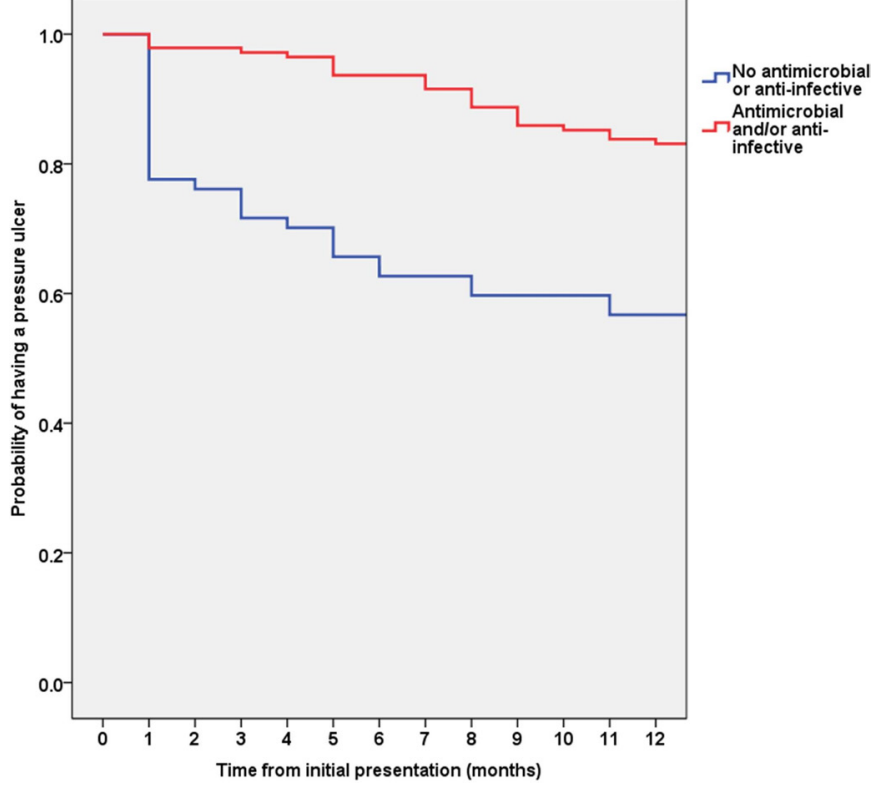

Figure 7 Kaplan-Meier time to healing analysis for patients who did and did not receive an antimicrobial dressing and/or prescribed systemic anti-infectives. The healing distribution between the two groups was significantly different (log rank (Mantel-Cox): $p<0.001$ ).

uninfected wound. This is consistent with our Burden of Wounds study. ${ }^{6716}$ The time to healing a wound is clearly an important factor in driving costs. Accordingly, the cost of PU management can be affected by a combination of resources required for dressing changes, complexity of some treatment regimens and infection. ${ }^{7}$ Hence, cost-effective management and healing of PUs remain a challenging problem.

PUs are generally a complication of serious acute or chronic illness in patient populations characterised by high levels of comorbidity, ${ }^{20}$ as observed in this study's cohort. PUs are a cross-specialty problem. ${ }^{20}$ Nevertheless, there appears to have been minimal involvement of specialist clinicians in the management of the wounds in this study's cohort. Only $3 \%$ of patients were recorded as having seen a tissue viability nurse and $12 \%$ of patients as having seen a specialist physician in the 12 months from initial presentation. It is possible that more patients received multidisciplinary care than those for whom it was recorded in the THIN database. However, there was minimal evidence of this within the records, and there was no evidence of a coordinated shared treatment plan.

There was no evidence in the patients' records that any of the PUs had been reported as a clinical incident. However, if incident reporting software (such as Datix) had been used, that would not necessarily be recorded in the THIN records, since the THIN database is essentially used for patient management and not incident reporting.

A category $1 \mathrm{PU}$ is an early manifestation of tissue damage without a break in the skin. It either resolves or progresses into more significant tissue damage and ulceration. As the skin is intact with category 1 PUs, the damaged area will need protection and monitoring, 
but dressings are not always necessary. ${ }^{21}$ The outcomes reported in this study are based on the highest grading recorded for the wound, and in $95 \%$ of cases they are the only grading reported. The data on dressing usage (table 4) would suggest that a number of the category 1 wounds may have progressed to skin breakdown or were initially assessed incorrectly as category 1 . Although soft polymer and foam dressings may, in some cases, be used on intact skin, it is unlikely that antimicrobials or hydrogels would be appropriate dressings in this situation. Nevertheless, all the PUs classified as category 1 damage in this cohort resolved, although $14 \%$ took $>3$ months to resolve. This, along with the recorded dressing usage suggest that some of these wounds may have involved a degree of skin breakdown, which was not reflected in a recategorisation of the pressure damage.

This study highlights the apparent lack of treatment planning, re-assessment and re-evaluation of care for most patients with a PU in the community. The patients' combination of dressings and bandages remained unchanged for the length of time they had the PU, and there was no correlation between wound duration and senior involvement in direct patient care. Dressing selection should be based on an individual patient's requirements and should consider a patient's pain and tolerance, position of the ulcer, amount of exudate and frequency of dressing change. ${ }^{10}$ Ideally, a dressing that promotes a warm, moist wound healing environment should be used to treat category 2, 3 and 4 PUs. ${ }^{10}$ However, several systematic reviews found alginates to be no different to other dressings in treating PUs, ${ }^{22}$ and it is unclear whether foam dressings or hydrogel dressings are more or less clinically effective compared with alternative dressings in treating PUs. ${ }^{23}$ Of even more concern is that a recently published network meta-analysis was unable to determine which (if any) dressings or topical agents are most likely to heal PUs, and whether any of the treatments examined are more effective than saline gauze. ${ }^{25}$

There was minimal documentation in the patients' records regarding the provision of pressure redistributing devices to a patient's home, possibly reflecting the lack of transfer of documentation from Social Services to the patients' records. One recent study in Oxford found that only one-third of pressure-redistributing devices provided to patients with a PU were used as recommended. ${ }^{26}$ NICE recommends the use of pressure relieving devices for all adults with a PU. However, neither this document nor any other that the authors could find discuss how the use of such devices should be monitored. ${ }^{10}$ Clearly, improving management practices could generate better outcomes for patients and would be cost-effective for the NHS.

Other measures that could help overcome some of the problems encountered in clinical practice and achieve better outcomes include:

- Improving diagnostic support and implementing integrated progressive care pathways with defined trigger points for senior involvement and onward referral for specialist care.
- Assessment of a patient's nutritional status and provision of supplements, if indicated.

- Improving co-ordination and documentation between health and social care in relation to the provision of pressure redistributing devices.

- Prescribing systemic antibiotics and antiseptics if there is any clinical evidence of systemic sepsis or spreading cellulitis. $^{19}$

These measures are consistent with the NICE guidelines ${ }^{10}$ and should help improve wound-healing rates and reduce infection. This in turn should reduce workload and associated healthcare resource use and lead to reductions in the cost of wound care. NICE also recommends that patients with a PU are not routinely offered either negative pressure wound therapy, unless it is necessary to reduce the number of dressing changes (eg, in a wound with a large amount of exudate) or hyperbaric oxygen therapy and electrotherapy. ${ }^{10}$ The decision to debride a PU, particularly the use of conservative sharp debridement or surgical debridement, should be based on the amount of necrotic tissue, the category, size and extent of the PU and a patient's comorbidities. ${ }^{10}$

The NHS has a number of ongoing national PU prevention campaigns. ${ }^{8}$ These include 'Stop the Pressure' campaign, which aims to eliminate avoidable PUs, ${ }^{8}$ and 'React to Red', which includes an education and competency framework and which was initially designed specifically for staff working in care homes, but is now being used across all sectors, with the aim of reducing the incidence of PUs. ${ }^{8}$

Despite the impact of these ongoing PU prevention strategies, we predict that PU management is going to remain challenging. The number of new PUs in the UK has been estimated to rise to 200000 in 2017/2018 and is predicted to cost the NHS an estimated $£ 1.74$ billion in the first 12 months from onset, if the annual prevalence continues to increase unchecked. ${ }^{16}$ These costs would be in addition to the cost of managing the existing PUs, which can only be reduced by improving outcomes and healing rates. Clearly, training non-specialist nurses in preventative strategies and the appropriate management of PUs is a prerequisite to overcoming some of the problems encountered in clinical practice and to achieving better health outcomes than those currently being observed.

\section{Study limitations}

The advantages and disadvantages of using patients' records in the THIN database for health economic studies in wound care have been previously discussed. ${ }^{6}$ In summary, the advantage of using the database is that the patient pathways and associated resource use are based on real-world evidence derived from clinical practice. However, the analyses were based on clinicians' entries into their patients' records and inevitably subject to a certain amount of imprecision and lack of detail. Moreover, the computerised information in the database is collected by GPs and nursing teams for clinical care purposes and not for health economics research. 
Prescriptions issued by GPs and practice nurses are recorded in the database, but it does not specify whether the prescriptions were dispensed or detail patient compliance with the product. The patients' records do not directly refer to multiple PUs. The authors accept that some patients may have had more than one PU, but these data were not accurately or consistently documented. However, in many ways the number of wounds per se is extraneous as we are not addressing the cost of treating a wound, but the cost of managing a patient with a PU until the healing of the 'last' wound. Additionally, the accuracy of wound descriptors and other terminology have not been validated, but does reflect real-world documentation in clinical practice. The consistent application of wound descriptors across all healthcare providers would allow more accurate reporting of PU categories, improve clinical management and resource utilisation and should optimise patient outcomes. A wound assessment minimum data set has been developed within NHS England to support clinical practice, documentation and reported quality standards (Commissioning for Quality and Innovation (CQUIN) ) ${ }^{27}$ Despite these limitations, it is the authors' opinion that the real-world evidence contained in the THIN database has provided a useful perspective on the management of PUs in the community in the UK and the associated costs.

The analysis was truncated at 12 months. Hence, the study does not consider the potential impact of those wounds that remained unhealed beyond the study period. Also excluded is the potential impact of managing hospital inpatients with a PU and those being cared for in nursing/residential homes. The analysis only considered NHS resource use and associated costs for the 'average patient' and was not stratified according to gender, comorbidities, disease-related factors and level of clinicians' skills. Costs incurred by non-NHS organisations, patients' costs and indirect societal costs as a result of patients being absent from work were also excluded from the analysis. However, patients' mean age was $>65$ years, so it is unlikely that many were in employment.

\section{CONCLUSION}

The real-world evidence in this study provides important insights into a number of aspects of PU management in clinical practice in the community in the UK that have been difficult to ascertain from other published studies. Additionally, it provides the best estimate available of NHS resource use and costs with which to inform policy and budgetary decisions pertaining to managing these wounds. Clinical and economic benefits to both patients and the NHS could accrue from strategies that focus on (a) wound prevention, (b) improving wound-healing rates and (c) reducing infection. Clinicians managing PUs may wish to consider the findings from this study when making treatment decisions.
Contributors JFG designed the study, managed the analyses, performed some analyses, checked all the other analyses and wrote the manuscript. GWF conducted much of the analyses. KRV and PV scrutinised the analyses, suggested further analyses, helped interpret some of the findings. All the authors were involved in revising the manuscript and gave final approval. JFG is the guarantor of this work and, as such, had full access to all the data in the study and takes responsibility for the integrity of the data and the accuracy of the data analysis.

Funding This analysis was originally commissioned and part funded by the National Institute for Health Research (NIHR) Wound Prevention and Treatment Healthcare Technology Co-operative (NIHR WoundTec HTC), Bradford Institute for Health Research, Bradford, West Yorkshire, UK and part funded by Smith \& Nephew Medical Limited, Hull, East Riding of Yorkshire, UK.

Disclaimer The study's sponsors had no involvement in the study design, the collection, analysis and interpretation of the data, the writing of this manuscript and the decision to submit this article for publication. The views expressed in this article are those of the authors and not necessarily those of the NHS, the NIHR, the Department of Health or Smith \& Nephew Medical Limited.

\section{Competing interests None declared.}

Patient consent Not required.

Ethics approval Ethics approval to use anonymised patients' records from the THIN database for this study was obtained from the Research Ethics Committee that appraises studies using the THIN database (reference number 13-061).

Provenance and peer review Not commissioned; externally peer reviewed.

Data sharing statement The THIN data set cannot be shared as this restriction was a condition of the ethics approval obtained from the Research Ethics Committee (reference number 13-061).

Open access This is an open access article distributed in accordance with the Creative Commons Attribution Non Commercial (CC BY-NC 4.0) license, which permits others to distribute, remix, adapt, build upon this work non-commercially, and license their derivative works on different terms, provided the original work is properly cited and the use is non-commercial. See: http://creativecommons.org/ licenses/by-nc/4.0/

(C) Article author(s) (or their employer(s) unless otherwise stated in the text of the article) 2018. All rights reserved. No commercial use is permitted unless otherwise expressly granted.

\section{REFERENCES}

1. The National Pressure Ulcer Advisory Panel. NPUAP. NPUAP pressure injury stages. $2016 \mathrm{http}: / / w w w . n p u a p . o r g / r e s o u r c e s /$ educational-and-clinical-resources/npuap-pressure-injury-stages/.

2. Vanderwee K, Clark M, Dealey C, et al. Pressure ulcer prevalence in Europe: a pilot study. J Eval Clin Pract 2007;13:227-35.

3. Gefen A. Tissue changes in patients following spinal cord injury and implications for wheelchair cushions and tissue loading: a literature review. Ostomy Wound Manage 2014;60:34-45.

4. Bergstrom N, Braden B, Kemp M, et al. Predicting pressure ulcer risk: a multisite study of the predictive validity of the Braden Scale. Nurs Res 1998;47:261-9.

5. National Pressure Ulcer Advisory Panel and European Pressure Ulcer Advisory Panel and Pan Pacific Pressure Injury Alliance. Prevention and Treatment of Pressure Ulcers: Quick Reference Guide. Osborne Park, Western Australia: National Pressure Ulcer Advisory Panel and European Pressure Ulcer Advisory Panel and Pan Pacific Pressure Injury Alliance, 2014.

6. Guest JF, Ayoub N, Mcllwraith T, et al. Health economic burden that wounds impose on the National Health Service in the UK. BMJ Open 2015;5:e009283.

7. Guest JF, Ayoub N, Mcllwraith T, et al. Health economic burden that different wound types impose on the UK's National Health Service. Int Wound J 2017;14.

8. House of Lords Hansard. House of Lords debate on developing a strategy for improving the standards of wound care in the NHS. 2017 https://hansard.parliament.uk/lords/2017-11-22/debates/6C57E65AA04D-449B-82E9-C836F088A696/NHSWoundCare.

9. Department of Health. The NHS outcomes framework. 2014 https:// www.gov.uk/government/uploads/system/uploads/attachment_data/ file/256456/NHS_outcomes.pdf.

10. National institute for Health and Care Excellence (NICE). Pressure ulcers: prevention and management of pressure ulcers. NICE clinical guideline 179. 2014 https://www.nice.org.uk/guidance/CG179. 
11. NHS Digital. Read codes. 2018 https://digital.nhs.uk/article/1104/ Read-Codes (accessed 10 Mar 2018).

12. Blak BT, Thompson M, Dattani H, et al. Generalisability of The Health Improvement Network (THIN) database: demographics, chronic disease prevalence and mortality rates. Inform Prim Care 2011;19:251-5.

13. Curtis L, Burns A. Unit costs of health and social care 2016. University of Kent, Personal Social Services Research Unit, Canterbury. 2016 http://www.pssru.ac.uk/project-pages/unit-costs/ unit-costs-2016/ (accessed 12 Dec 2017).

14. Department of Health. NHS reference costs 2015/16. https://www. gov.uk/government/publications/nhs-reference-costs-2015-to-2016 (Accessed 12 Dec 2017).

15. Drug Tariff. Drug tariff. 2016 https://www.drugtariff.co.uk (accessed 12 Dec 2017).

16. Guest JF, Vowden K, Vowden P. The health economic burden that acute and chronic wounds impose on an average clinical commissioning group/health board in the UK. J Wound Care 2017;26:292-303.

17. Bennett G, Dealey C, Posnett J. The cost of pressure ulcers in the UK. Age Ageing 2004;33:230-5.

18. Dealey C, Posnett J, Walker A. The cost of pressure ulcers in the United Kingdom. J Wound Care 2012;21:261-6.

19. Norman G, Dumville JC, Moore ZE, et al. Antibiotics and antiseptics for pressure ulcers. Cochrane Database Syst Rev 2016;4:CD011586.
20. Coleman S, Gorecki C, Nelson EA, et al. Patient risk factors for pressure ulcer development: systematic review. Int J Nurs Stud 2013;50:974-1003

21. Jones ML. Prevention and treatment of superficial pressure damage. Nursing and Residential Care 2012;14:14-20.

22. Dumville JC, Keogh SJ, Liu Z, et al. Alginate dressings for treating pressure ulcers. Cochrane Database Syst Rev 2015:CD011277.

23. Dumville JC, Stubbs N, Keogh SJ, et al. Hydrogel dressings for treating pressure ulcers. Cochrane Database Syst Rev 2015:CD011226.

24. Walker RM, Gillespie BM, Thalib L, et al. Foam dressings for treating pressure ulcers. Cochrane Database Syst Rev 2017;10:CD011332.

25. Westby MJ, Dumville JC, Soares MO, et al. Dressings and topical agents for treating pressure ulcers. Cochrane Database Syst Rev 2017;6:CD011947.

26. Jackson D, Durrant L, Bishop E, et al. Health service provision and the use of pressure-redistributing devices: mixed methods study of community dwelling individuals with pressure injuries. Contemp Nurse 2017;53:378-89.

27. Coleman S, Nelson EA, Vowden P, et al. Development of a generic wound care assessment minimum data set. J Tissue Viability 2017;26:226-40. 